\title{
In Tune with their Scientific Philosophies and Theories of Language, Skinner's Writing Style is Simpler, Punchier, and Less Abstract than Chomsky's
}

\author{
Cynthia Whissell* \\ Laurentian University, Canada
}

*Corresponding Author: Cynthia Whissell, Laurentian University, Canada

\begin{abstract}
This research compares the writing styles of Skinner (1957) and Chomsky (1965) in two books on the theory of language. In tune with their theories which occupy opposite poles of the cognition-behavior dimension, Chomsky's writing is significantly more complex and includes longer words, longer sentences, more abstract words, and more passive words while Skinner's writing is simpler, including shorter words and sentences, more concrete words, and more active words. Samples the size of a page (350 words) are easily differentiated in terms of authorship by a discriminant function analysis $(p<.001$, canonical correlation $=.89)$ based onword activation, the Automated Readability Index, and the use of more rare words. The discriminant function generalizes successfully (80\% correct classification) to new samples of text.
\end{abstract}

Keywords: Skinner, Chomsky, language, style, emotion

\section{INTRODUCTION}

Psychology is defined as the scientific study of behavior and mental processes, and, in the 1960s and 1970s, B. F. Skinner and Noam Chomsky were held to represent the two poles of this definition with respect to the psychology of language (Benjafield, 2015, p. 395; Hergenhahn, 2009, p. 616). Skinner was a logical positivist and a behaviorist: he attributed all behaviors, even the most complex ones such as language, to learning on the basis of reinforcement and he refused to theorize about "mind" because it could not be measured directly in any objective way. Chomsky was a cognitive psychologist who focused on the role of the mind in performance and especially in language: his theory was human-centered. In an article written half-way between Skinner and Chomsky's day and the present, Andressen (1991) noted that Chomsky rode a wave of increasing preference for cognitive, mind-based psychology to greater and greater fame while Skinner's behaviorism, still employed in many practical settings, was at a theoretical disadvantage due to its waning popularity. Spear (2007, p. 374 ), emphasized the rising popularity of cognition and neuroscience in the psychology literature: he also provided evidence of the dramatic fall in the popularity of behaviorism as a keyword for psychology articles published after 1970.

The Google Ngram viewer ${ }^{1}$ was employed to search for the appearance of the two names (Chomsky and Skinner) in books scanned by Google that were published between 1955 and 2000.The name Skinner had a background rate of 25 mentions per million words in the earliest third of the $20^{\text {th }}$ century, so data for this name were corrected by subtracting this as a constant. Fig. 1 displays occurrences or mentions of Chomsky and Skinner over the entire period. Mentions of Chomsky rose to a high in the 1970's and 1980's when cognitive psychology was experiencing its wave of popularity. After this date, mentions remain higher for Chomsky than for Skinner. The enduring importance of these theorists to current discussions is supported by the rate at which their names were still used at the end of the $20^{\text {th }}$ century (Fig. 1).As well, Google Trends ${ }^{2}$ data for 2018 and most of 2019 (consulted in October, 2019) showed a roughly equal employment of the names of the two scientists as Google search terms. The number of Google searches for either author were at about the rate of $1 / 12^{\text {th }}$ of the Google searches involving William Shake speare: interest in the theoretical positions that Skinner and Chomsky represent remains high in the $21^{\text {st }}$ century.

\footnotetext{
${ }^{1}$ https://books.google.com/ngrams

${ }^{2}$ https://trends.google.com/trends/
} 
In Tune with their Scientific Philosophies and Theories of Language, Skinner's Writing Style is Simpler, Punchier, and Less Abstract than Chomsky's

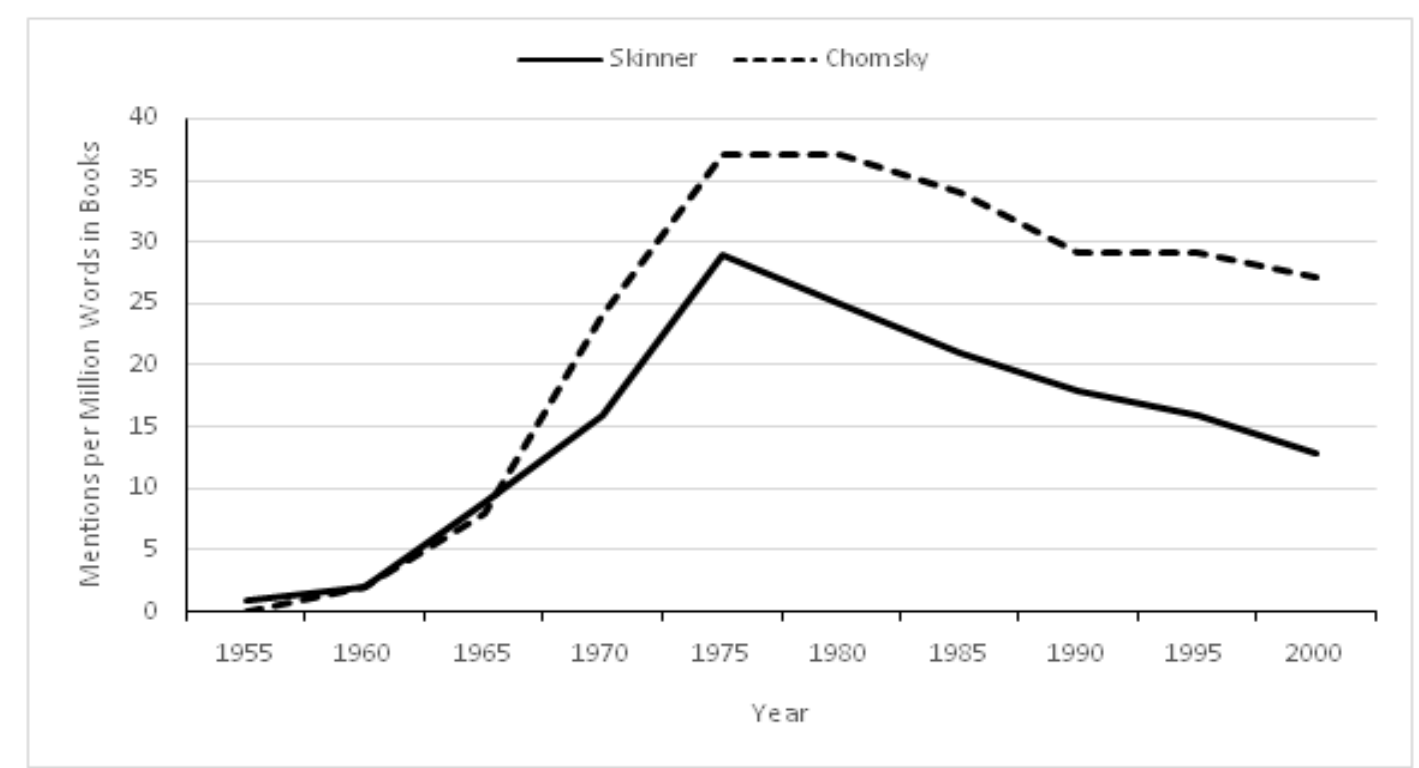

Figure1: Mentions of the names of Chomsky and Skinner* between 1955 and 2000 (according to Google Ngram)

*Mentions of Skinner have been corrected for background level.

The research described in this article examines the language of two famous works that exemplify the Skinner-Chomsky disparity. Skinner published his work on Verbal Behavior in 1957, and Chomsky, after first publishing an article critiquing this work (1959), among other things, published his own book on Aspects of the Theory of Syntax in 1965.The main prediction of the research described in this paper is that the theorist who had the more complex, mind-based, theory of language (Chomsky) would use more complex and abstract language to describe his ideas than the theorist who viewed language as an operant behavior that did not require a presumption of mind (Skinner).In other words, the two authors were hypothesized to extend characteristics of their scientific philosophies into their actual writing. The complexity of written language is often measured in terms of word length, word abstraction, sentence length, and the employment of rare words. Word length and sentence length are employed in the calculation of complexity indexes such as the Flesch-Kincaid index and the Fog index (Stajner, Evans, Orasa, \&Mitkov, 2012) as well as the Automated Readability Index (Smith $\&$ Senter, 1967).Word abstraction and rarity are more difficult to measure, but tools do exist that can estimate them (Whissell 1998, 2009).

\section{METHOD}

Samples of close to 6000 words were copied from the beginning of Skinner's 1957 book and Chomsky's 1965 work. All the words in each source were scored using the Dictionary of Affect in Language (2009) which provides two emotional and one concreteness score for close to 9000 common English words. Word concreteness, the opposite of abstraction, was established by asking raters how easily they could form a mental picture of a word. If they could do this easily the word was considered concrete; if a word could not be readily pictured or envisioned it was abstract. Pleasantness and activation, the emotional dimensions, were established by asking participants to rate a word on the scales of Unpleasant - Pleasant or Passive - Active. The scale employed in this research for all three measures has a transformed norm for everyday English of 50 (Whissell, 2009).The Dictionary matching rate was $85 \%$ for Chomsky's word choices and $93 \%$ for Skinner's. Summary measures of pleasantness, activation, and concreteness are based only on words matched by the dictionary.

To establish their frequency in use, words were compared to the frequency of words in a sample of 348,000 words of everyday English (Whissell, 1998). According to an a priori decision, words with an (adjusted) frequency of 6 or less in 1,000,000 words ( 0 to 2 in the comparative sample) were considered rare. Table 1 provides examples of words scoring at the extreme end of each of the four scoring dimensions (pleasantness, activation, concreteness, and frequency).Word length was calculated in terms of the number of letters per word and sentence length in terms of the number of 
In Tune with their Scientific Philosophies and Theories of Language, Skinner's Writing Style is Simpler, Punchier, and Less Abstract than Chomsky's

words per sentence. The Automated Readability Index (Smith \&Senter, 1967) is a function of word length and sentence length. Higher scores indicate texts that are more complex and difficult to read and understand. All words are employed to estimate word and sentence length.

Table1: Samples of words from the two books scoring at the extreme end of four different scoring dimensions

\begin{tabular}{|l|l|}
\hline Common Words & Rare Words \\
Say & Dispositions \\
Must & Generative \\
Fact & Structuralist \\
\hline Concrete Words & Abstract Words \\
Muscles & Generally \\
People & Condition \\
Records & Principle \\
\hline Pleasant Words & Unpleasant Words \\
Friends & Unnecessary \\
Therapeutic & Against \\
Respect & Complex \\
\hline Active Words & Passive Words \\
Behavior & Component \\
Stimulation & Furthermore \\
Effort & Slowly \\
\hline
\end{tabular}

Besides the original samples of text, 10 additional subsamples of approximately one page in length were randomly chosen, five for each author. Two samples for each author were from the later sections of the two books previously utilized, while three were taken at random from another book by each writer: Skinner's The Behavior of Organisms (1938) and Chomsky's Syntactic Structure (1957).These additional samples were employed to test the generalizability of results based on the original samples.

\section{ReSUlts}

A multivariate general linear model was employed to compare continuous variables and $\chi^{2}$ analysis was employed for categorical ones (proportion of rare words, proportion of sentence-ending punctuations in ratio to words).Only words matched by the Dictionary of Affect were included in analyses of pleasantness, activation, and concreteness. The multivariate author effect for these variables was significant but weak (Pillais $\mathrm{F}_{3,10218}=15.32, \mathrm{p}<.001, \mathrm{p \eta}^{2}=.004$ ).In a separate analysis that included all words, there was a similarly weak univariate effect for word length $\left(\mathrm{F}_{1,11484}=10.32\right.$, $\left.\mathrm{p}=.001, \mathrm{p}^{2}=.001\right)$. Detailed univariate differences between the styles of the two authors are noted in Table 2.

Table2: Comparisons of Skinner's and Chomsky's works

\begin{tabular}{|l|l|l|l|l|}
\hline Variable & $\begin{array}{l}\text { Skinner } \\
\mathbf{( 1 9 5 7 )}\end{array}$ & $\begin{array}{l}\text { Chomsky } \\
(\mathbf{1 9 6 5})\end{array}$ & $\begin{array}{l}\text { p value and } \boldsymbol{\eta}^{\mathbf{2}} \\
\text { for all scored words }\end{array}$ & $\begin{array}{l}\boldsymbol{\eta}^{\mathbf{2}} \text { for 350 } \\
\text { Subsamples }\end{array}$ \\
\hline Pleasantness & 47.24 & 47.21 & $\mathrm{NSD}$ & 0 \\
\hline Activation & $49.83^{\mathrm{a}}$ & 47.26 & $\mathrm{p}<.001, \mathrm{p}^{2}=.004$ & .36 \\
\hline Concreteness & $47.28^{\mathrm{a}}$ & 41.81 & $\mathrm{p}<.001, \mathrm{p}^{2}=.002$ & .17 \\
\hline Word Length & 4.96 & $5.14^{\mathrm{a}}$ & $\mathrm{p}<.001=.001$ & .13 \\
\hline \% Rare Words & 11.5 & $19.1^{\mathrm{a}}$ & $\mathrm{p}<.001, \mathrm{~V}=.11$ & .28 \\
\hline Words/Sentence & 21.74 & $29.41^{\mathrm{a}}$ & $\mathrm{p}<.001\left(\chi^{2}\right)$ & .45 \\
\hline $\begin{array}{l}\text { Automated } \\
\text { Readability Index }\end{array}$ & $\begin{array}{l}12.8 \\
\left(7^{\text {th }} \text { Grade }\right)\end{array}$ & $\begin{array}{l}17.5 \\
\left(12^{\text {th }} \text { Grade }\right)\end{array}$ & -- & .48 \\
\hline
\end{tabular}

${ }^{a}$ This superscript denotes the significantly higher value.

\subsection{Two Different Styles}

Skinner and Chomsky did not differ in terms of the pleasantness of their words. However, Chomsky's words were more passive, more abstract, and longer than Skinner's. Chomsky employed more rare words and constructed longer sentences. On the other hand, Skinner's words were more active, more concrete, and shorter. He employed fewer rare words and constructed shorter sentences. The readability index for Skinner's work indicates that it was appropriate for Grade 7 students (about 1213 years old), while that of Chomsky's work that it was appropriate for early Grade 12 students in the 
In Tune with their Scientific Philosophies and Theories of Language, Skinner's Writing Style is Simpler, Punchier, and Less Abstract than Chomsky's

last year of high school. In rough terms, it would require at least four more years of schooling to understand Chomsky's writing than Skinner's.

\section{2. "Guessing" the Authorship of a Subsample of Text}

Subsamples of roughly 350 consecutive words (the exact number varied because of differing use of punctuation marks) were created by subdividing the sample for each source. A stepwise discriminant function analysis was conducted predicting author (Skinner or Chomsky) on the basis of word activation, word imagery, the proportional employment of rare words, and the Automated Readability Index for each subsample. Since the Index was computed based on word and sentence length, and since pleasantness evinced no difference between authors, these measures were not included in the analysis. The discriminant function was $100 \%$ successful in identifying authorship on the basis of three variables - the Index, activation, and the use of rare words. Standardized canonical discriminant function coefficients were 1.01, -.72 , and .65 respectively: samples with a high Index, more rare words, and a lower level of activation were predicted as being written by Chomsky. Prediction was significant as well as strong ( $\mathrm{p}<.001$, with a canonical correlation of .89). It is notable that when longer units of text are employed rather than single words, the effect sizes associated with differences between Skinner and Chomsky rise dramatically (last column of Table 2).This suggests that although it would be difficult to tell if a single word were a "Chomsky word" or a "Skinner word", the difficulty disappears when samples of about one page in length are employed: at this point authorship becomes perfectly clear.

\subsection{Generalizability of Results}

The discriminant function obtained for page-length samples was applied to the classification of the 10 additional samples of the same size to test its generalizability. The function correctly classified $8 / 10$ $(80 \%)$ of the additional samples. Miss-classified were Skinner's discussion of the question of induction and the discrimination of stimuli, which included many symbols (Behavior of Organisms, 1938, pp. 227-228) and Chomsky's argument for higher levels of analysis in language than single words (Aspects of a Theory of Syntax, 1965, p. 86-7). These errors suggest that Skinner could occasionally be more abstract and/or complex in his writing while Chomsky could occasionally be more succinct and/or straightforward.

\section{CONClusions}

In the lab, Skinner's research focused on tangible, directly observable responses such as bar presses and button pecks. His theory of language was an extension of this research and it also focused on the tangible and the observable. Chomsky, on the other hand, based his theory of language on ideas rather than lab results and his inclusion of the mind in his explanation of language necessitated the use of terms that made abstract inferences about the unobservable. The writing styles of the two authors are perfectly in tune with this difference: in the works studied here Skinner employed more concrete terms and wrote in a generally simpler manner while Chomsky wrote more abstractly and with greater complexity and passivity. These conclusions generalized successfully. It is both interesting and informative to realize that the language in which scientists argue their case is paradigmatic of their theories.

\section{REFERENCES}

[1] Andressen, J. (1991) Skinner and Chomsky: 30 years later or: the return of the repressed. The Behavior Analyst, 14, 49-60.

[2] Benjafield, J. G. (2015) A History of Psychology. $4^{\text {th }}$ Edition. Don Mills, Ontario: Oxford University Press.

[3] Chomsky, N. (1957) Syntactic Structures. The Hague: Mouton.

[4] Chomsky, N. (1959) Review of Skinner's Verbal Behavior. Language, 35, 26-58.

[5] Chomsky, N. (1965) Aspects of a theory of syntax. Cambridge, Mass.: MIT Press.

[6] Hergenhahn, B. R. (2009) An Introduction to the History of Psychology. $6^{\text {th }}$ Edition. Belmont, CA, USA: Wadsworth.

[7] Senter, R.J. \& Smith, E.A. (1967).Automated Readability Index. Wright-Patterson Air Force Base. AMRLTR-6620.

[8] Spear, J. H. (2007) Prominent schools or other active specialities? A fresh look at some trends in Psychology. Review of General Psychology, 11, 363-380. 
In Tune with their Scientific Philosophies and Theories of Language, Skinner's Writing Style is Simpler, Punchier, and Less Abstract than Chomsky's

[9] Skinner, B. F. (1938) The Behavior of Organisms. NY: Appleton-Century-Crofts.

[10] Skinner, B. F. (1957) Verbal Behavior. Englewood Cliffs, NJ: Prentice-Hall.

[11] Stajner, S., Evans, R., Orasan, C. \& Mitkov, R. (2012) What can readability measures really tell us about text complexity? In L. Rello, H. Saggion (Eds.), Proceedings of Workshop on natural language processing for improving textual accessibility, Istambul, pp. 14-22.

[12] Whissell, C. (1998). A parsimonious technique for the analysis of word-use patterns in English texts and transcripts. Perceptual and Motor Skills, 86, 595-613.

[13] Whissell, C. (2009).Using the revised Dictionary of Affect in Language to quantify the emotional undertones of samples of natural language.Psychological Reports, 105, 1-13.

Citation: Cynthia Whissell. In Tune with their Scientific Philosophies and Theories of Language, Skinner's Writing Style is Simpler, Punchier, and Less Abstract than Chomsky's. "International Journal on Studies in English Language and Literature (IJSELL), vol 7, no. 11, 2019, pp. 11-15. doi: http://dx.doi.org/10.20431/2347-3134.0711002.

Copyright: (C) 2019 Authors. This is an open-access article distributed under the terms of the Creative Commons Attribution License, which permits unrestricted use, distribution, and reproduction in any medium, provided the original author and source are credited. 